J. Clin. Chem. Clin. Biochem.

Vol. 28, 1990, pp. 107-111

(C) 1990 Walter de Gruyter \& Co. Berlin · New York

\title{
Lipid Screening in Paediatrics for Early Detection of Cardiovascular Risks ${ }^{1}$ )
}

\author{
By F. Buser, W. F. Riesen and R. Mordasini
}

Institute for Clinical and Experimental Research of the University of Berne, Lipid Laboratory, Tiefenau Hospital, Berne, Switzerland

(Received March 22/September 8, 1989)

Summary: The purpose of the study was to try to detect at an early stage the important cardiovascular risk factors associated with increased concentrations of blood lipids, notably cholesterol. The trial was based on the screening of 102 families, including 219 children, 8-18 years of age and their parents. A group of young adults, 19-25 years of age, was included in the study. All subjects were derived from a paediatric practice. In addition to total cholesterol, VLDL-, LDL-, HDL-cholesterol and apolipoproteins A-I and B were also measured. The study identified a significant number of school-children and adolescents with hyperlipidaemia, predominantly hypercholesterolaemias type II-A. There was a close relationship between their blood lipids and those of their parents. The study demonstrates the importance of including parents in studies of this kind. Total cholesterol proved to be a reliable parameter for screening. The value of apolipoproteins in such screening is discussed.

\section{Introduction}

It is generally agreed that an increased concentration of blood lipids, notably cholesterol, is one of the most important risk factors in cardiovascular disease. Although it is well known that anomalies in lipid metabolism may be found in children, lipid determinations are not normally included in paediatric screening programmes for the early detection of risk factors. However, in view of the potential prevention of cardiovascular disease this age group could be important. This topic has already led to a series of studies of different age ranges and has yielded various results. General agreement about the screening of children however does not exist $(1-5)$. It was the purpose of the present study to gather in a paediatric practice more information about the value of such screening.

\footnotetext{
1) The laboratory work of this study was supported in part by a grant from the Swiss National Science Foundation.
}

\section{Subjects and Methods}

Subjects

The study was based upon the screening of blood lipids in families, i.e. parents and their children between the age of 8 and 18 years. The collective included 102 parent couples and their 116 sons and 103 daughters. In a second phase of the study, a group of young adults, 19 to 25 years old, from the same families, was also included. All families were recruited at random from a normal paediatric practice, belonging predominantly to middle class residents of the city of Berne.

After 3-4 years, it was possible to re-examine the majority of the study group, children and parents. In addition, children were monitored repeatedly up to 8 years, until the end of puberty. Individuals were not tested during periods of illness.

\section{Methods}

Total cholesterol, VLDL-, LDL-, HDL-cholesterol were measured by enzymatic methods in sera collected after $12 \mathrm{~h}$ fasting. VLDL were prepared with the aid of an Air Fuge (Beckman). $\mathrm{LDL}$ were precipitated with phosphotungstate and $\mathrm{Mg}^{2+}(6)$. Apolipoprotein B was measured by a non-competitive ELISA, using LDL as a primary, and OMEGA lipid fraction control serum (Travenol) as a secondary standard (7). Apolipoprotein A-I was determined by electro-immuno-assay with sheep antibodies (8), using isolated apolipoprotein A-I as a primary, and OMEGA lipid fraction control serum as secondary standard. 


\section{Results}

Figure 1 shows the level of total cholesterol and its lipoprotein fractions in all participants in the study during their development. An important peak for total cholesterol and LDL-cholesterol is noted at $8-12$ years of age in boys and to a lesser extent in girls. This is followed by a gradual decrease during puberty, reaching a minimum at $18-19$ years of age for boys and at 16-17 years for girls. After puberty, there is a distinct rise in the mean concentration of total cholesterol and LDL-cholesterol, especially in males. The level of HDL-cholesterol is remarkably constant, although the mean levels for males decrease slightly during puberty towards a permanently lower level, while HDL values for females increase slowly after puberty towards a stable higher level. VLDLcholesterol remains at about the same level during the development of both sexes during childhood and adolescence, but clear differences appear after 20-25 years of age, values for males showing a marked upward trend, and those for females showing a similar but less pronounced increase.

Triacylglycerol is not included in the study, since the interpretation of this parameter as a risk factor for coronary heart disease is not clear. Figure 2 shows the distribution of apolipoprotein A-I and B concentrations in the study group. For the two sexes, the mean values for apolipoprotein A-I are very similar until puberty, after which the values show a distinct rise in females, whereas the values rise slightly in males, then decrease. Similarly, the mean values for apolipoprotein B stay close together for both sexes at a more-or-less steady level, separating only at $20-25$ years of age, when the values for males show a steep rise, those for females staying much lower.

Figure 3 shows mean values of the atherogenic indices, HDL-cholesterol/LDL-cholesterol and apolipoprotein A-I/apolipoprotein B. The values for both sexes lie close together until puberty, but separate thereafter, showing a downward trend which is more pronounced for males, especially in the case of the HDLcholesterol/LDL-cholesterol ratio.

Figure 4 and table 1 demonstrate the close hereditary relationship between children and their parents with respect to cholesterol values. High and low parental values correspond to high and low mean levels, respectively, in both their sons and daughters.

Our lipid screening provided the following data for total cholesterol for boys and girls and their parents.

A fraction of 0.41 of boys presented levels below 4.7 $\mathrm{mmol} / 1(<180 \mathrm{mg} / \mathrm{dl}) ; 0.11$ had a moderate risk level of $>5.7-6.7 \mathrm{mmol} / 1(>220-260 \mathrm{mg} / \mathrm{dl}) ; 0.06$ pos-

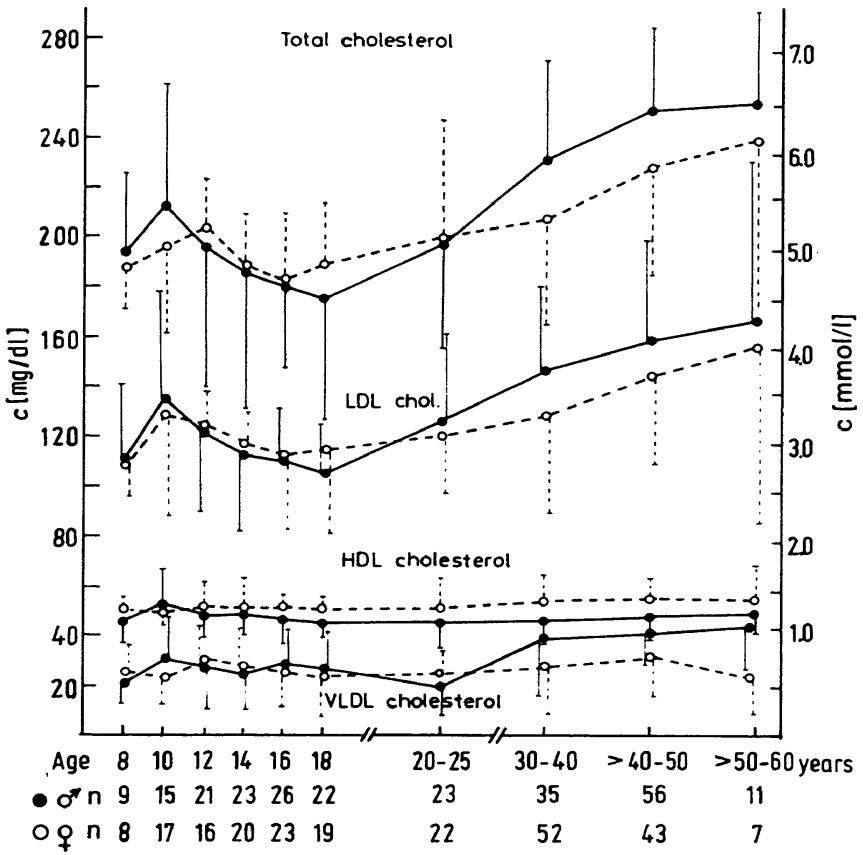

Fig. 1. Development of total cholesterol and its lipoprotein fractions in a family study.

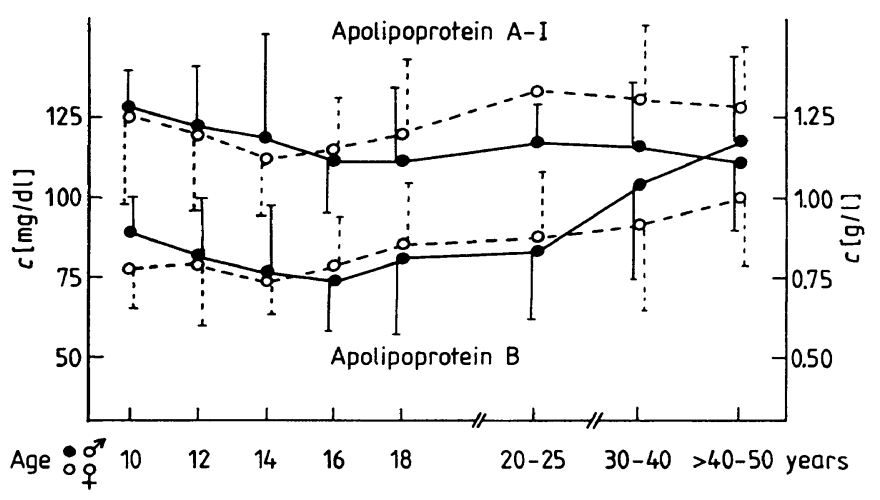

Fig. 2. Apolipoprotein A-I and B values in a family study.

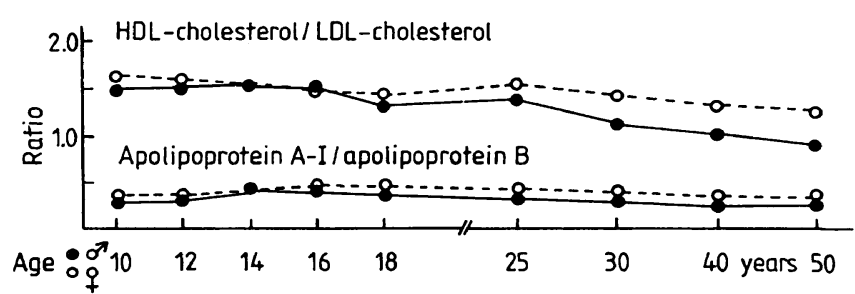

Fig. 3. Atherogenic indices HDL-cholesterol/LDL-cholesterol and apolipoprotein A-I/apolipoprotein B in a family study.

sessed a high risk level of $>6.7 \mathrm{mmol} / \mathrm{l}(>260 \mathrm{mg} / \mathrm{dl})$, of which 0.025 showed a very high risk level of $>7.7$ $\mathrm{mmol} / 1$ ( $>300 \mathrm{mg} / \mathrm{dl}$ ) ( 2 cases of primary familial hyperlipidaemia type II-A and 1 case of a secondary type (nephrosis)), while 0.13 of the fathers also presented the same levels. 

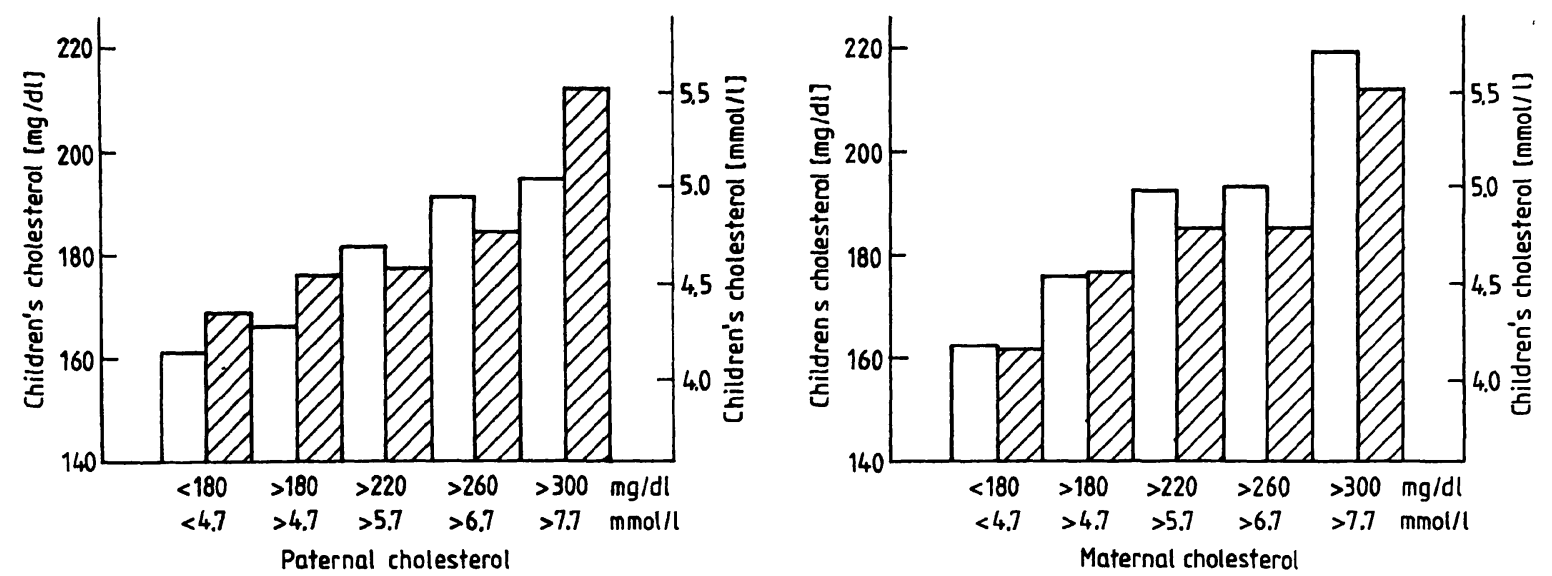

Fig. 4. Cholesterol values in a family study showing an hereditary relationship.

$\mathbb{Z}$ male

$\square$ female

Tab. 1. Correlation between cholesterol values $(\overline{\mathrm{x}} \pm \mathrm{SD})$ of children and parents.

\begin{tabular}{|c|c|c|c|c|c|}
\hline \multirow[t]{2}{*}{ Relationship } & \multirow[t]{2}{*}{$\mathbf{N}$} & & \multicolumn{2}{|l|}{ Cholesterol } & \multirow[t]{2}{*}{$\mathbf{r}$} \\
\hline & & & $(\mathrm{mmol} / \mathrm{l})$ & $(\mathrm{mg} / \mathrm{dl})$ & \\
\hline Fathers/sons & $81 / 116$ & $\begin{array}{l}\text { fathers } \\
\text { sons }\end{array}$ & $\begin{array}{l}6.3 \pm 1.24 \\
4.7 \pm 0.90\end{array}$ & $\begin{array}{l}244 \pm 48 \\
183 \pm 35\end{array}$ & 0.33 \\
\hline Fathers/daughters & $70 / 103$ & $\begin{array}{l}\text { fathers } \\
\text { daughters }\end{array}$ & $\begin{array}{l}6.2 \pm 1.13 \\
4.7 \pm 0.72\end{array}$ & $\begin{array}{l}241 \pm 44 \\
183 \pm 27\end{array}$ & 0.42 \\
\hline Mothers/sons & $81 / 116$ & $\begin{array}{l}\text { mothers } \\
\text { sons }\end{array}$ & $\begin{array}{l}5.6 \pm 1.08 \\
4.7 \pm 0.85\end{array}$ & $\begin{array}{l}218 \pm 42 \\
182 \pm 34\end{array}$ & 0.33 \\
\hline Mothers/daughters & $70 / 103$ & $\begin{array}{l}\text { mothers } \\
\text { daughters }\end{array}$ & $\begin{array}{l}5.6 \pm 1.13 \\
4.7 \pm 0.74\end{array}$ & $\begin{array}{l}219 \pm 44 \\
184 \pm 29\end{array}$ & 0.54 \\
\hline
\end{tabular}

A fraction of 0.53 of girls presented levels below 4.7 $\mathrm{mmol} / \mathrm{l}(<180 \mathrm{mg} / \mathrm{dl}) ; 0.07$ had moderate risk levels of > $>5.7 .7 \mathrm{mmol} / 1$ (>220-260 mg/dl), while none was in the high risk group $>6.7 \mathrm{mmol} / 1$ ( $>260$ $\mathrm{mg} / \mathrm{dl}$ ); 0.12 of their mothers were however in this latter group.

In both sexes secondary alimentary hyperlipidaemias of varying degree, with or without certain undefined hereditary factors, were frequently found. After 3-4 years, it was possible to re-check approximately 0.7 of the original family study group, parents and children. In addition, most children, especially those with cholesterol concentrations higher than $4.7 \mathrm{mmol} / \mathrm{l}$ ( $>180 \mathrm{mg} / \mathrm{dl}$ ), were re-checked at $1-3$ year intervals, up to 7-8 years, until the end of puberty. A fraction of $0.12-0.13$ of the children who originally had more than $4.7 \mathrm{mmol} / \mathrm{l}(>180 \mathrm{mg} / \mathrm{dl}$ ) later possessed lower cholesterol values. A fraction of $0.04-0.05$ of those who originally had less than $4.7 \mathrm{mmol} / 1(<180 \mathrm{mg} / \mathrm{dl})$ later developed higher levels. The majority, however, remained within the original range, above or below
$4.7 \mathrm{mmol} / 1(180 \mathrm{mg} / \mathrm{dl})$, although during puberty there was a general downward trend. Individuals who had displayed moderately elevated cholesterol levels at puberty were re-examined in their early twenties; one additional case (0.01) was found among the sons with a very high risk level $(>7.7 \mathrm{mmol} / \mathrm{l} ;>300 \mathrm{mg} / \mathrm{dl})$, and two more cases among the girls, both with high risk levels ( $>6.7 \mathrm{mmol} / 1 ;>260 \mathrm{mg} / \mathrm{dl}$ ). Each of these was an example of familial hyperlipidaemia type II-A. Among the children there were two cases (0.01), one of each sex, which were compatible with a heterozygous type of familial hyperlipoproteinaemia.

During the 3-4-year examination period, the parents displayed little change in cholesterol levels, although there was a slight decrease (around 10-15\%) in those with elevated levels who had been on a diet. In contrast, there was a slight increase in those who had not dieted and also in those females in menopause.

On the whole, the individual values of apolipoproteins A-I and B in our study confirm the results of our lipoprotein screening. 


\section{Discussion}

Although our study is based upon a relatively small number of subjects, it nevertheless allowed us to detect a series of elevated cholesterol levels in children and their parents. The total- and LDL-cholesterol levels (fig. 1) of the pre-pubertal peak in boys and girls, between 8 and 12 years of age, were very pronounced. After the well known decrease during and after puberty, we noted again relatively high mean total and LDL-cholesterol values in adults, especially in fathers. It was of interest to note that the total and LDLcholesterol values showed similar trends to those found in other, large-scale, studies (9). The relatively high mean cholesterol values which we found in both sexes correspond to general findings in the Swiss population $(10,11)$. It must also be noted that most of the families in this study were in no way alerted to the relationship between blood cholesterol levels and diet, a fact which holds true for the majority of our general population.

The graphs showing apolipoprotein A-I and B values (fig. 2) mirror the HDL- and LDL-cholesterol data and clearly demonstrate the difference between the sexes after puberty. The same holds true for the atherogenic indices, HDL-cholesterol/LDL-cholesterol and apolipoprotein A-I/apolipoprotein B (fig. 3).

It is well known, that in addition to alimentary factors, hereditary also play a major role (12). This relationship is clearly evident in our subjects (fig. 4; tab. 1).

Apolipoproteins A-I and B were included in our study because these parameters have proven to be equally or even more reliable than lipoproteins for the detection of coronary heart disease risks $(13-15)$. This holds especially true for apolipoprotein B for some special cases of familial coronary heart disease $(16-18)$.

The benefit attached to lipid screening in paediatrics is still controversial, but we do not believe that it is best to wait until a parent has suffered coronary disease before examining the children. It must also be noted that the parental histories in almost all our subjects had been silent. Our findings support the view that screening for lipids should in fact be started in all children (19). The question concerning the best age to start however remains open and cannot be answered by our relatively small study. For practical reasons we started our trial at a lower age limit of 7-8 years, which corresponded to the school entry period, and proved to be favourable for family cooperation. The 7-8-year bracket precedes the prepubertal peak of total and LDL-cholesterol values, and is perhaps the most suitable for routine screening (20). Cholesterol screening in the very young child has given unsatisfactory results, except in families with known familial hypercholesterolaemia $(21,22)$. As an upper limit for acceptable cholesterol values for children and adolescents we chose those proposed by the Consensus Conference (23), i. e. approximately $4.7 \mathrm{mmol} / \mathrm{l}(180 \mathrm{mg} / \mathrm{dl})$.

Later re-examination, during puberty and thereafter proved to be in various cases an indispensable aid for diagnosis and prognosis, particularly in relation to elevated cholesterol values. Thus, re-checking allowed us to identify a number of false "positive" and false "negative" values. Individuals whose values remained elevated during puberty, the period normally associated with minimum levels, were followed into their twenties, thus permitting an evaluation of their risk status. Late re-examination proved especially helpful in females, who tend to lay behind males in developing high risk levels.

With regard to the results of our search for the early detection of cardiovascular risks, the fraction of cases with severe hyperlipoproteinaemia was small $(0.02-$ 0.03 ), although it reached 0.06 when re-checks in the early twenties were included. However, any single finding is important, because it contributes to the assessment of measures that might be taken to reduce the risks in young people before too much damage has occurred. Furthermore, the early detection of those many cases of hyperlipidaemia, which are due mainly to unfavourable alimentary factors, seems to be essential. Such cases must be considered to be at potentially high risk, and they might also be anticipated from the parental screening.

Therapeutic measures for our children with elevated cholesterol levels were limited to the recommendation of a diet low in cholesterol and saturated fat. Medication was restricted to cholestyramine and was applied only to a few adolescents who had very high levels of cholesterol.

We advocate the inclusion of parents in paediatric lipid screening, since we have seen that it is helpful in establishing a diagnosis in children. It is, of course, also valuable for detecting risk factors in the parents themselves, and it assists the introduction of dietary control measures within the family. This kind of combined screening could be an important contribution to the field of preventive medicine, and it could appropriately be undertaken primarily by the paediatrician, who has easy access to young adults through his contact with their young children. 
Our study showed that total cholesterol is a reliable parameter for the detection of cardiovascular risks in children, if duly re-checked during puberty. Additional parameters, such as lipoprotein fractions and apolipoproteins, notably in normolipidaemic individuals with familial coronary heart disease risks, are

\section{References}

1. Levy, R. I. \& Rifkind, B. M. (1973) Diagnosis and management of hyperlipidemia in infants and children. Am. J. Cardiol. 31, 547-555.

2. Kwiterovich, P. O. (1977) Pediatric Aspects of Hyperlipoproteinemia. In: Hyperlipidemia, Diagnosis and Therapy (Rifkind, B. M. \& Levy, R. L., eds.) New York: Grune \& Stratton, pp. 249-279.

4. Boulton, T. J. C. (1979) The validity of screening for hypercholesterinaemia at different ages from 2 to 17 years. Aust. N. Z. J. Med. 9, 542-546.

4. Orchard, T. J., Donahue, B. S., Kuller, L. H., Hodge, P. N. \& Drash, A. L. (1983) Cholesterol screening in childhood: Does it predict adult hypercholesterinemia? The Beaver county experience. J. Pediatr. 103, 687-691.

5. Kwiterovich, P. O. (1986) Biochemical, clinical, epidemiologic, genetic and pathologic data in the pediatric age group relevant to the cholesterol hypothesis. Pediatrics $78,349-$ 359.

6. Burstein, M., Scholnick, H. R. \& Morfin, R. (1970) Rapid method for the isolation of lipoproteins from human serum precipitation with polyanions. J. Lipid. Res. 11, 583-595.

7. Riesen, W. F., Sturzenegger, E., Imhof, C. \& Mordasini, R. (1986) Quantification of apolipoprotein B by polyclonal and monoclonal antibodies. Clin. Chim. Acta 154, 29-40.

8. Mordasini, R. \& Riesen, W. (1980) Apo A-I. Electroimmuno assay and radio immuno assay for the quantification of the apolipoproteins A-I and I-II. J. Clin. Chem. Clin. Biochem. 18, 917-920.

9. Lipid Research Clinic Population Studies Book (1978) pp. $28-46$.

10. Micheli, H., Stähelin, H. B. \& Junod, B. (1981) Distribution $\mathrm{du}$ cholestérol plamatique dans quatre villes suisses. Schweiz. Med. Wochenschr., suppl. 12, 24-31.

11. Burnand, B., Rickenbach, M., Hausser, D., Barazzoni, F., Domenighini, G. \& Gutzwiller, F. (1987) Cholestérol, pression artérielle et fumée de cigarette dans la population Suisse: le projet MONICA. Social- und Präventivmedizin 32, 69-77.

12. Kupke, I. R. (1985) On the advantage of screening kindergarten children for atherogenesis-related risk indicators. Prog. Clin. Biol. Res. 188, 93-99.

13. Riesen, W. F., Mordasini, R., Salzmann, C., Theler, A. \& Gurtner, H. P. (1980) Apoproteins and lipids as discriminators of severity of coronary heart disease. Atherosclerosis $37,157$. useful in establishing a detailed diagnosis and in classifying particular cases.

\section{Acknowledgement}

The authors wish to thank Ms E. Schlumpf and Ms E. Ischi for excellent technical assistance.
14. Sveger, T. \& Fex, G. (1983) Apolipoprotein A-I and B levels in adolsescents; a trial to define subjects at risk for coronary heart disease. Acta Paediatr. Scand. 72, 499504.

15. Solakivi-Jaakkola, T., Nikkari, T., Viikari, J., Akerblom, H. K., Räsänen, L., Uhari, M., Lähde, P., Pesonen, E., Pietikäinen, M. \& Suoninen, P. (1985) Atherosclerosis precursors in Finnish children and adolescents. VI. Serum apolipoproteins A-I and B. Acta Paediatr. Scand. Suppl. $318,119-125$.

16. Hamsten, A., Iselius, L., Dahlen, G. \& de Faire, U. (1986) Genetic and cultural inheritance of serum lipids, low and high density lipoprotein cholesterol and serum apolipoproteins A-I, A-II and B. Atherosclerosis 60, 199-208, ISSN 0021-9150.

17. Van-Stiphout, W. A., Hofman, A., Kruijssen, H. A., Vermeeren, R. \& Groot, P. H. (1986) Is the ratio apo B/apo A-I an early predictor of coronary atherosclerosis? Atherosclerosis $62,79-82$.

18. Kwiterovich, P., Beaty, T., Bachorik, P., Chen, J., Franklin, F., Georgopoulos, L. \& Sniderman, A. (1988) Pediatric hyperlipoproteinemia: the phenotypic expression of hyperapobetalipoproteinemia in young probands and their parents. Prog. Clin. Biol. Res. 255, 89-108, ISSN 0361-7742.

19. Nader, P. R., Taras, H. L. \& Sallis, J. F. (1987) Adult heart disease prevention in childhood: a national survey of pediatricians' practices and attitudes. Pediatrics 79, 843-850.

20. Jacobson, M. S. \& Lillienfeld, D. E. (1988) The pediatrician's role in atherosclerosis prevention. J. Pediatr. 112, 836-841.

21. Boulton, T. J., Craig, I. H. \& Hill, G. (1979) Screening of cord blood low-density-lipoprotein cholesterol in the diagnosis of familial hypercholesterinemia: a study of 2000 infants. Acta Paediatr. Scand. 68, 363-670.

22. Andersen, G. E., Lous, P. \& Friis-Hansen, B. (1979) Screening for hyperlipoproteinemia in 10'000 Danish newborns. Follow-up studies in 522 children with elevated cord serum VLDL-LDL-cholesterol. Acta Paediatr. Scand. 68, $541-$ 545.

23. Consensus Conference (1985) Lowering blood cholesterol to prevent heart disease. J. Am. Med. Ass. 253, 20802086.

Dr. F. Buser, M.D.

Halen 8

CH-3037 Herrenschwanden 
